crying. ${ }^{8}$ Nevertheless, they are rarely so large and certainly never as prolonged as those seen in smothering. They do not occur during sleep. Secondly, at about one minute after the onset of the episode there was a series of large breaths occurring at a relatively slow rate with a characteristically prolonged expiratory phase. This "gasping" respiratory pattern is a typical response to severe arterial hypoxaemia. ${ }^{10}$ Thirdly, the episode was associated with a severe degree of sinus tachycardia.

Finally, some 60 seconds after the onset of the episode, there were the large slow waves and a subsequent isoelectric baseline on the electroencephalogram typical of cerebral hypoxaemia. It is important to compare the comparatively long time taken for electroencephalographic changes to occur after smothering with the comparatively short latency in prolonged expiratory apnoea, in which severe hypoxaemia is extremely rapid in onset. ${ }^{8}$ Thus unconsciousness and electroencephalographic changes from cerebral hypoxaemia are present after only 30 seconds in this latter condition, whereas in smothering around 60-70 seconds of complete airway obstruction was present before the associated changes were detected. This adds weight to the hypothesis that prolonged expiratory apnoea is associated with severe ventilatoryperfusion mismatch, probably resulting from widespread alveolar atelectasis. ${ }^{1718}$

It was clearly crucial that both mothers should receive psychiatric treatment. It is difficult to know how much to believe of the histories given concerning their childhood, as so much deception was woven into their stories. Nevertheless, it may be relevant that both mothers reported severe physical abuse from their fathers during adolescence. ${ }^{1920}$ If this can be validated it may have important implications with regard to prevention, diagnosis, and treatment.

In conclusion smothering is a comparatively rare but dangerous and preventable cause of hypoxaemic episodes in infants and young children. Diagnosis by video camera surveillance produces unequivocal evidence, avoids the need for nursing and medical staff to enter into confrontation with the mother in court, and prevents the trauma of confronting the mother with an incorrect suspicion. Unequivocal evidence is crucial to the adequate protection of the child. Future studies may show that a specific pattern on multi- channel recordings of physiological variables is pathognomonic of imposed apnoea, thus avoiding the need for video surveillance.

We thank Dr J Bridson and Dr A Williams for referring the patients and for their help in diagnosing this condition and caring for the families concerned. DPS is supported by Nellcor and the National SIDS Foundation and VAS by the Nuffield Foundation. We are particularly grateful to members of the Chelsea division of the Metropolitan Police for their compassion and professionalism in dealing with these difficult problems.

\section{References}

1 Meadow R. Fictitious epilepsy. Lancet 1984;ii:25-8.

2 Berger D. Child abuse simulating "near miss" sudden infant death syndrome. $\mathcal{I}$ Pediatr 1979;95:554-6.

3 Rosen CL, Frost JD Jr, Bricker T, Tarnow JD, Gillette PC, Dunlavy S. Two siblings with recurrent cardiorespiratory arrest: Munchausen syndrome by proxy or child abuse? Pediatrics 1983;71:715-20.

4 Minford AM. Child abuse presenting as apparent "near-miss" sudden infant death syndrome. BrMed f 1981;282:521.

5 Geelhoed GC, Pemberton PJ. SIDS, seizures, or 'sophaegeal reflux? Another manifestation of Munchausen syndrome by proxy. Med F Aust 1985;143:357-8.

6 McKinlay I. Munchausen's syndrome by proxy. BrMed $\mathcal{F}$ 1986;293:1308.

7 Meadow R. Management of Munchausen syndrome by proxy. Arch Dis Child 1985;60:385-93.

8 Southall DP, Talbert DG, Johnson P, et al. Prolonged expiratory apnoea-a disorder resulting in episodes of severe arterial hypoxaemia in infants and young children. Lancet 1985;ii:571-7.

9 Southall DP, Stebbens V, Abraham N, Abraham L. Prolonged apnoea with severe arterial hypoxaemia resulting from complex partial seizures. Dev Med Child Neurol (in press).

10 Dawes G. Fetal and neonatal physiology. Chicago: Yearbook Medical Publications, 1968:141-59.

11 Lugaresi E, Cirignotta F, Rossi G, Santucci M, Montagna P. Infantile behavioural regression and respiratory impairment. Neuropediatrics 1984;15:211-4.

12 Meadow R. Munchausen syndrome by proxy. The hinterland of child abuse. Lancet 1977;ii:343-5.

13 Emery JL. Child abuse and "near-miss cot death." Br Med f 1981;282:821.

14 Taylor EM, Emery JL. Two-year study of the causes of postperinatal deaths classified in terms of preventability. Arch Dis Child 1982;57:668-73.

15 Emery JL. Infanticide, filicide, and cot death. Arch Dis Child 1985;60:505-7.

16 Beal J, Blom-Cooper L, Brown B, Marshall P, Mason M. A child in trust. The report of the panel of inquiry into the circumstances surrounding the death of Jasmine Beckford. London Borough of Brent: Kingswood Press, 1985.

17 Southall DP, Talbert DG, Johnson P, et al. Prolonged expiratory apnoea and hypoxaemia. Lancet 1985;ii:1125-6.

18 Talbert DG, Southall DP. A bimodal form of alveolar behaviour induced by a defect in lung surfactant-a possible mechanism for sudden infant death syndrome. Lancet 1985;ii:727-8.

19 Korbin JE. Childhood histories of women imprisoned for fatal child maltreatment. Child Abuse and Neglect 1986;10:331-8.

20 Tuteur W, Glotzer M. Further observations on murdering mothers. F Forensic Sci 1966;11: 373-83.

(Accepted 13 March 1987)

\title{
Third trimester placental grading by ultrasonography as a test of fetal wellbeing
}

\author{
JEAN PROUD, ADRIAN M GRANT
}

\begin{abstract}
In a study of $\mathbf{2 0 0 0}$ unselected pregnant women the development of a mature placental appearance (grade 3 ) on ultrasonography by 34-36 weeks' gestation, observed in $15 \%$ of cases, was associated with maternal smoking, low parity, low maternal age, and being white. These women had an increased risk of problems during labour and their babies had an increased risk of low birth weight, poor condition at birth, and perinatal death. The women were
\end{abstract}

Peterborough Maternity Unit, Peterborough PE3 6BP

JEAN PROUD, SCM, MTD, sister in charge of scanning department

National Perinatal Epidemiology Unit, Radcliffe Infirmary, Oxford OX2 6HE ADRIAN M GRANT, DM, MRCOG, epidemiologist

Correspondence to: Dr Grant. randomly allocated to two groups: in one group the result of the placental grading was reported to the clinician responsible for care; in the second the result was noted but not reported. There was a significant decrease in the risk of perinatal death in the group where the grading was known. This reduction was responsible for a difference in the principal outcome index, a heterogeneous group of measures of mortality and morbidity, but this difference was not significant.

This study alone does not justify routine late scanning, and further, larger trials are required. Nevertheless, the results do provide a basis for the reporting of placental grading when ultrasound examination is performed during the third trimester.

\section{Introduction}

The appearance of the placenta on ultrasound examination changes progressively with advancing gestational age, but the speed of these changes varies from pregnancy to pregnancy. Grannum et al first 
described four stages (grades 0-3) of placental development that they used to relate placental maturation to fetal pulmonary maturity.' Placental grading has only limited usefulness in this respect, ${ }^{2}$ but other investigators later reported an association between grade 3 placental maturation and subsequent obstetric problems, in particular intrauterine growth retardation and fetal distress in labour. . $^{3.5}$

There were two objectives of this study. The first was to test the hypothesis that early placental maturation, possibly through a relation with maternal smoking, is a predictor of subsequent obstetric problems. The second was to investigate in a randomised controlled trial whether clinical action taken on the basis of placental grading improved perinatal outcome.

\section{Patients and methods}

The design of the study was based on the ultrasound scanning programme that existed at Peterborough maternity unit. The policy was for all women booked for delivery in the hospital to have three routine scans. The first was performed in early pregnancy to confirm gestational age and to rule out multiple pregnancy or any fetal or maternal abnormality. The second and third scans were performed at about 30-32 weeks' and 34-36 weeks' gestation respectively. In these, fetal presentation, measurements of the head and abdominal circumference, exclusion of specific fetal abnormalities, liquor volume assessment, the position of the placenta, and (from 1982) placental grading were reported. It was also policy to report the grade of the placenta at any other ultrasonographic examination during the third trimester.

Women attending the scanning department during the last trimester of pregnancy were given a written description of the study. Provided that they had no objections to participating they were then randomly allocated to one of two groups. In the first group placental grading was reported to the obstetricians for all ultrasound examinations thereafter. In the second group the placenta was graded but the grading was recorded only for the purposes of the study and was not reported in the casenotes (other details of the examination were reported as usual). Once entered in the study the women remained in their allocated group for all subsequent scans. The 1:1 randomisation was arranged in balanced blocks of varying size. The procedure: for allocation was organised by a research assistant who was not concerned with the scanning or the clinical care of the participants. Each recruit was first allocated a trial number. A correspondingly numbered, sealed, opaque envelope (prepared in Oxford) was then attached to the casenotes and later opened by the ultrasonographer to show the trial allocation. Details of the placental grading were not made available for any women in the second group. Otherwise the clinical management of all women in the trial was left entirely to the obstetrician responsible for care and no attempt was made to standardise the clinical response to early placental maturation.

A standardised system was used for ultrasonographic placental assessment. ${ }^{1}$ The grading was based on the appearance of the bulk of the placenta rather than the edges. All scans were performed by two experienced midwife ultrasonographers. They had a high level of agreement in their grading of placentas: in a series of 36 women who were independently assessed by both examiners there was agreement in all but one case, which was graded 0 by one and 1 by the other. The final trial size of 2000 was dictated by a change of staff in the scanning department. A newly promoted ultrasonographer did not have sufficient experience to grade placentas reliably as judged by a low level of agreement with an experienced ultrasonographer (JP) when a series of placentas was assessed by both independently.

The observational data of the study refer to the 1468 pregnant women who were scanned at 34 to 36 weeks' gestation. The predictive properties of grade 3 placental appearance at this stage of pregnancy for five prespecified measures of outcome were expressed in terms of sensitivity, specificity, predictive values, and odds ratio, with the $95 \%$ confidence interval of the odds ratio calculated using Miettinen's method. ${ }^{6}$ The birth weight for gestational age standards used were those of Secher $e t a l .^{7}$

The main hypothesis tested in the randomised controlled trial was that knowledge of the placental grade would lead to clinical action that reduced the number of babies (who were not lethally malformed) who (a) died between trial entry and one week after delivery; or $(b)$ had Apgar scores of less than 4 at one minute or less than 7 at five minutes; or $(c)$ were admitted to the special care nursery. If the true prevalence of this combination of measures of adverse outcome was $8 \%$, a trial of this size had a $65 \%$ chance of a significant result $(\alpha=0.05)$ if the real effect was a reduction by a third; the power was $85 \%$ if the true reduction was by $40 \%$. The $\chi^{2}$ and Student's $t$ tests were used where appropriate.

\section{Results}

PLACENTAL GRADE 3 MATURATION AT 34-36 WEEKS

Of the 2000 women studied, $1468(73 \%)$ were scanned at 34 to 36 weeks, $247(12 \%)$ had a single scan at about 32 weeks, and the remainder were scanned once before 34 weeks and then for a second time after 36 weeks (almost invariably at 37 weeks). A grade 3 placenta at $34-36$ weeks, observed in $15 \%$ of cases, was found to be significantly associated with low maternal age (age $<20 ; 48(22 \%)$ grade $3 v 134(11 \%)$ grades $0-2)$; nulliparity 149 $(67 \%) v 601(48 \%)$; and being white $211(95 \%) v 1113(89 \%)$. The association with maternal smoking at booking was confirmed: $83(37 \%)$ women with grade 3 placentas were smokers compared with $287(23 \%)$ women with grades 0-2. A grade 3 placental appearance at 34-36 weeks was associated with an increased risk of meconium staining of the liquor, fetal distress in labour, low Apgar score, low birth weight, and perinatal death (table I). Secondary analyses showed that the association with low birth weight reflected both increased risk of preterm delivery (odds ratio $1 \cdot 7,95 \%$ confidence interval 0.9 to 3.0 ) and increased risk of low birth weight for gestational age (odds ratio $1 \cdot 3,95 \%$ confidence interval $0 \cdot 8$ to $2 \cdot 0$ ).

\section{THE RANDOMISED CONTROLLED TRIAL}

The 2000 subjects were randomly divided into two equal sized groups. The mean gestational age at entry -and therefore at the first scan-was 31.7 weeks in the first group (placental grading reported to the clinician) and 31.8 in the second group. Randomisation produced groups which were also comparable in other important respects (table II).

Table III shows the clinical management of the trial groups. The main response to the report of early placental maturation seems to have been oestriol estimation. Despite the fact that induction of labour was less common in the first group, delivery tended to occur earlier. This primarily reflected a tendency for spontaneous labour to occur earlier in this group and a high rate of induction in the study population after 41 completed weeks. A caesarean section performed before labour had started and induction of labour were in fact more common in this group before 41 completed weeks. Meconium staining and no visible liquor were both more common in the second group, where the clinician did not know the placental grading $(p<0.025)$, and this was only partly explained by the difference between the trial groups in gestational age at delivery.

Table IV shows the neonatal outcome. Seventy one babies in the first group fulfilled one or more of the criteria of the prime measure of outcome compared with 83 in the second group. This estimated reduction in risk of $14 \%$ was not significant ( $95 \%$ confidence intervals $38 \%$ reduction to $16 \%$ increase). It did, however, largely reflect a difference in perinatal mortality (2 $v 10$ deaths not caused by lethal malformations, $\mathrm{p}<0.05$ ).

\begin{tabular}{|c|c|c|c|c|c|c|c|c|c|c|}
\hline . & $\begin{array}{l}\text { No }(\%) \text { in } \\
\text { placental } \\
\text { grade 0-2 }\end{array}$ & $\begin{array}{c}\text { No }(\%) \text { in } \\
\text { placental } \\
\text { grade } 3\end{array}$ & $\begin{array}{l}\text { Prevalence } \\
\text { in total (\%) }\end{array}$ & $\begin{array}{c}\text { Sensitivity } \\
(\%)\end{array}$ & $\begin{array}{c}\text { Specificity } \\
(\%)\end{array}$ & $\begin{array}{l}\text { Positive } \\
\text { predictive } \\
\text { value } \\
(\%)\end{array}$ & $\begin{array}{l}\text { Negative } \\
\text { predictive } \\
\text { value } \\
(\%)\end{array}$ & Odds ratio & $\begin{array}{c}95 \% \\
\text { Confidence } \\
\text { interval }\end{array}$ & p Value \\
\hline $\begin{array}{l}\text { Meconium stained liquor } \\
\text { Emergency caesarean section for fetal distress } \\
\text { Apgar score }<7 \text { at } 5 \text { minutest } \\
\text { Low birth weightt } \\
\text { Perinatal death† }\end{array}$ & $\begin{array}{r}93(7 \cdot 5) \\
29(2 \cdot 3) \\
16(1 \cdot 3) \\
69(5 \cdot 5) \\
3(0 \cdot 2)\end{array}$ & $\begin{array}{l}32(14 \cdot 3) \\
14(6 \cdot 2) \\
7(3 \cdot 1) \\
24(10 \cdot 6) \\
4(1 \cdot 8)\end{array}$ & $\begin{array}{l}(8 \cdot 5) \\
(2 \cdot 9) \\
(1 \cdot 6) \\
(6 \cdot 3) \\
(0 \cdot 5)\end{array}$ & $\begin{array}{l}26 \\
33 \\
30 \\
26 \\
57\end{array}$ & $\begin{array}{l}86 \\
85 \\
85 \\
85 \\
85\end{array}$ & $\begin{array}{r}14 \\
6 \\
3 \\
11 \\
1 \cdot 8\end{array}$ & $\begin{array}{l}93 \\
98 \\
99 \\
95 \\
99 \cdot 8\end{array}$ & $\begin{array}{l}2 \cdot 1 \\
2 \cdot 8 \\
2 \cdot 5 \\
2 \cdot 0 \\
7 \cdot 5\end{array}$ & $\begin{array}{l}1 \cdot 4 \text { to } 3 \cdot 2 \\
1 \cdot 5 \text { to } 5 \cdot 1 \\
1 \cdot 0 \text { to } 5 \cdot 9 \\
1 \cdot 3 \text { to } 3 \cdot 3 \\
2 \cdot 1 \text { to } 26 \cdot 6\end{array}$ & $\begin{array}{l}<0.001 \\
<0.005 \\
<0.05 \\
<0.025 \\
<0.005\end{array}$ \\
\hline
\end{tabular}

$\star$ Placental grade $0-2=1245$; grade $3=223$.

$\dagger$ Rates are for babies and include twins. Placental grade 0-2=1256; grade $3=227$. 
Table $\mathrm{V}$ gives details of all the perinatal deaths subdivided by the Baird classification system. ${ }^{89}$ The one case of unexplained death in the first group had a grade 3 placental appearance at 36 weeks. No special clinical action was taken on the basis of this information.

Of the (bottom) eight cases in the second group (table V), which might have been affected by knowledge of the placental grade, three had developed grade 3 appearance by 36 weeks and a further two had grade 3 placenta before term.

\section{Discussion}

The two ultrasonographers who performed all the scans in this study showed near perfect agreement in their placental grading. Nevertheless, the subjective element of the test may result in important interobserver variation (as was our experience when a

TABLE II-Descriptive characteristics of trial groups at entry

\begin{tabular}{lcc}
\hline & $\begin{array}{c}\text { First group } \\
\text { (placental grading } \\
\text { reported to clinician) } \\
(\mathrm{n}=1000)\end{array}$ & $\begin{array}{c}\text { Second group } \\
\text { (placental grading not } \\
\text { reported to clinician) } \\
(\mathrm{n}=1000)\end{array}$ \\
\hline Maternal age (completed years) (mean (SD)) & $25 \cdot 8(5 \cdot 5)$ & $25 \cdot 3(5 \cdot 1)$ \\
Nulliparity & 487 & 509 \\
Social class: & 233 & 241 \\
$\quad$ 1 and 2 & 287 & 258 \\
3 & 454 & 484 \\
4 and 5 & 26 & 17 \\
Not known & 101 & 107 \\
Ethnic origin (non-white) & 236 & 272 \\
Smoker (when booked) & 341 & 350 \\
Consultant: & 334 & 328 \\
A & 325 & 322 \\
B & 950 & 960 \\
C & $31 \cdot 7(1 \cdot 0)$ & $31 \cdot 8(1 \cdot 0)$ \\
Scan performed when women booked & 137 & 155 \\
Gestational age at entry (weeks)(mean(SD)) & & \\
Pre-existing medical problems & & \\
\hline
\end{tabular}

TABLE III-Clinical management, labour, and delivery

\begin{tabular}{|c|c|c|}
\hline & $\begin{array}{l}\text { First group } \\
\text { (placental grading } \\
\text { reported to } \\
\text { clinician) } \\
(\mathbf{n}=1000)\end{array}$ & $\begin{array}{l}\text { Second group } \\
\text { (placental grading } \\
\text { not reported to } \\
\text { clinician) } \\
(\mathbf{n}=1000)\end{array}$ \\
\hline \multicolumn{3}{|l|}{ No of scans after entry: } \\
\hline 1 & 115 & 132 \\
\hline 2 & 800 & 782 \\
\hline 3 & 71 & 77 \\
\hline $4-5$ & 14 & 9 \\
\hline Oestriol estimation & 268 & $208^{\star \star \star}$ \\
\hline \multicolumn{3}{|l|}{ Cardiotocography performed: } \\
\hline No & 813 & 800 \\
\hline \multirow{2}{*}{\multicolumn{3}{|c|}{ Antenatal admissions: }} \\
\hline & & \\
\hline No & 312 & 304 \\
\hline Mean stay (SE) & $2.52(0.22)$ & $2 \cdot 33(0 \cdot 19)$ \\
\hline \multicolumn{3}{|l|}{ Onset of labour: } \\
\hline Spontaneous & 717 & 701 \\
\hline Induced & 218 & 237 \\
\hline Caesarean section before labour & 59 & 55 \\
\hline Not known & 6 & 7 \\
\hline \multicolumn{3}{|l|}{ Quality of liquor during labour: } \\
\hline Clear & 778 & 748 \\
\hline Meconium stained & 70 & $101^{\star \star}$ \\
\hline Blood stained & 73 & 70 \\
\hline No liquor & 16 & 21 \\
\hline Not applicable & 52 & 48 \\
\hline Not known & 11 & 12 \\
\hline \multicolumn{3}{|l|}{ Gestational age at delivery (weeks): } \\
\hline$<37$ & 68 & 61 \\
\hline $37-41$ & 925 & 928 \\
\hline $42+$ & 1 & 4 \\
\hline Not known & 6 & 7 \\
\hline Mean (SE) (weeks) & $39.09(0.05)$ & $39 \cdot 22(0.05)$ \\
\hline Mode of delivery: & $(n=1014)$ & $(n=1011)$ \\
\hline Normal vaginal & 727 & 709 \\
\hline Instrumental & 133 & 143 \\
\hline Emergency caesarean & 73 & 81 \\
\hline Elective caesarean & 62 & 59 \\
\hline Vaginal breech & 13 & 12 \\
\hline Not known & 6 & 7 \\
\hline
\end{tabular}

$\star \star \mathrm{p}<0.025 . \quad \star \star \star \mathrm{p}<0.01$.
TABLE IV-Neonatal outcome

\begin{tabular}{|c|c|c|}
\hline & \multicolumn{2}{|c|}{ No of babies } \\
\hline & $\begin{array}{l}\text { First group } \\
\text { (placental grading } \\
\text { reported to clinician) } \\
(n=1014)\end{array}$ & $\begin{array}{l}\text { Second group } \\
\text { (placental grading not } \\
\text { reported to clinician) } \\
\quad(n=1011)\end{array}$ \\
\hline \multicolumn{3}{|l|}{ Apgar score: } \\
\hline$<4$ at one minute & 30 & 29 \\
\hline$<7$ at five minutes & 12 & $25^{\star}$ \\
\hline Intubation in delivery ward & 20 & 17 \\
\hline \multicolumn{3}{|l|}{ Birth weight: } \\
\hline$<2500 \mathrm{~g}$ & 72 & 75 \\
\hline$<10$ th centile weight for gestational age & 90 & 88 \\
\hline $\operatorname{Mean}(\mathrm{SD})(\mathrm{g})$ & $3285(521)$ & $3305(555)$ \\
\hline Admission to special care nursery & 48 & 60 \\
\hline Neonatal seizures & 1 & 2 \\
\hline Antepartum stillbirth & $0(1)+$ & $9(3)+$ \\
\hline Early neonatal death & $2(1) \dagger$ & $1(0) \dagger$ \\
\hline Late neonatal death & $0(0) \dagger$ & $0(0) \dagger$ \\
\hline \multirow{2}{*}{\multicolumn{3}{|c|}{ Subgroups of perinatal deaths: $\ddagger$}} \\
\hline & & \\
\hline Congenital anomaly & 2 & 3 \\
\hline Miscellaneous & 1 & 1 \\
\hline Antepartum haemorrhage & 0 & 2 \\
\hline Pre-eclampsia & 0 & 2 \\
\hline Unexplained $\geqslant 2500 \mathrm{~g}$ & 1 & 3 \\
\hline Unexplained $<2500 \mathrm{~g}$ & 0 & 2 \\
\hline \multirow{2}{*}{\multicolumn{3}{|c|}{$\begin{array}{l}\text { Perinatal death and/or Apgar score }<4 \text { at one } \\
\text { minute and/or Apgar score }<7 \text { at five minutes }\end{array}$}} \\
\hline & & $83(3) \dagger$ \\
\hline
\end{tabular}

new ultrasonographer joined the department). This may explain the prevalence rates different from ours reported from some hospitals ${ }^{10}$ but not from others. ${ }^{11}$ Clearly such variation could prejudice the usefulness of the test, and standardisation of interpretation is important before contemplating the introduction of this test into clinical practice.

For the purpose of assessing the predictive properties of early placental maturation we chose to concentrate on 34 to 36 weeks. Routine late ultrasound scans are commonly performed at this stage of pregnancy and elective delivery is a much safer option than it is before 34 weeks. Clinical action taken on the basis of a test result may alter the outcome against which the test is being compared and lead to an underestimate or overestimate of the test's performance. For this reason the intention had been to restrict the evaluation of the predictive properties of early placental maturation to the group in which the grading results had been withheld from the clinicians. In the event the results in the two trial groups in these respects were so similar that we chose to include all cases with scans in this gestational age period to give a larger sample size.

The study has confirmed the associations between early placental maturation and problems in labour, poor condition at birth, and low birth weight. As table I shows, a grade 3 placenta at 34-36 weeks is associated with an estimated increase of between 2 and 8 in the odds of having these conditions. None of the sensitivities are high, however, indicating that only a few babies with these conditions (with the possible exception of normally formed stillbirths) will show the signs of early placental maturation. Furthermore, low prevalence of the conditions coupled with specificities around $85 \%$ result in low predictive values of positive test results. In other words, although the chances of subsequent obstetric problems are apparently more than doubled in association with early placental maturation, only a few of these cases will actually develop a problem. This suggests that the finding of a grade 3 placenta at this gestation should lead to increased surveillance and supplementary tests of fetal wellbeing rather than to more definitive obstetric intervention.

The study also confirmed the association of early placental maturation with smoking in early pregnancy. Crawford et al observed differences between smokers and non-smokers in ultrasound placental texture as early as the second trimester and these persisted to delivery. ${ }^{12}$ To put our findings another way, $23 \%$ of smokers developed grade 3 appearance between 34 and 36 weeks compared with $13 \%$ of non-smokers. The observed relation with 
TABLE V-Details of the perinatal deaths

\begin{tabular}{|c|c|c|c|c|c|c|}
\hline $\begin{array}{r}\text { Case } \\
\text { No }\end{array}$ & Baird class & $\begin{array}{c}\text { Gestation } \\
\text { (completed } \\
\text { weeks) }\end{array}$ & $\begin{array}{c}\text { Birth } \\
\text { weight } \\
\text { (g) }\end{array}$ & $\begin{array}{c}\text { Scan } \\
\text { performed } \\
\text { (weeks of } \\
\text { gestation) }\end{array}$ & $\begin{array}{c}\text { Placental } \\
\text { grading }\end{array}$ & Comments \\
\hline \multicolumn{7}{|c|}{ First group (placental grading reported to clinician) } \\
\hline 1 & Congenital anomaly & 38 & 1991 & $\begin{array}{l}32 \\
34\end{array}$ & $\begin{array}{l}2 \\
2\end{array}$ & Potter's syndrome, stillbirth \\
\hline 2 & Congenital anomaly & 39 & 3130 & 33 & 2. & Spina bifida \\
\hline 3 & Miscellaneous & 38 & 2990 & $\begin{array}{l}32 \\
35\end{array}$ & $\begin{array}{l}0 \\
2\end{array}$ & Good condition at birth. Neonatal infection. Sudden death on fourth day. \\
\hline 4 & Unexplained $(\geqslant 2500 \mathrm{~g})$ & 39 & 3000 & $\begin{array}{l}32 \\
36\end{array}$ & $\begin{array}{l}2 \\
3\end{array}$ & Poor condition at birth, ? birth asphyxia \\
\hline \multicolumn{7}{|c|}{ Second group (placental grading not reported to clinician) } \\
\hline 5 & Congenital anomaly & 37 & 2100 & 32 & $\begin{array}{l}2 \\
3\end{array}$ & Hydrocephaly, stillbirth, other abnormalities \\
\hline 6 & Congenital anomaly & 34 & 1580 & 32 & 0 & Hydrocephaly, stillbirth \\
\hline 7 & Congenital anomaly & 39 & 2950 & 32 & 1 & Spina bifida, stillbirth \\
\hline 8 & Miscellaneous & 39 & 2940 & $\begin{array}{l}32 \\
36\end{array}$ & $\begin{array}{l}0 \\
1\end{array}$ & Good condition at birth. Sudden unexplained death on third day \\
\hline 9 & Antepartum haemorrhage & 34 & 2100 & 31 & 0 & Abruptio placentae at 34 weeks, fresh stillbirth \\
\hline 10 & Antepartum haemorrhage & 39 & 3133 & $\begin{array}{l}32 \\
37 \\
39\end{array}$ & $\begin{array}{l}2 \\
2 \\
3\end{array}$ & Bleeding on and off for the week before macerated stillbirth \\
\hline 11 & Pre-eclampsia & 32 & 1050 & 32 & 3 & Proteinuric hypertension, small for gestational age on ultrasonography, macerated stillbirth \\
\hline 12 & Pre-eclampsia & 37 & 2820 & $\begin{array}{l}30 \\
34\end{array}$ & $\begin{array}{l}1 \\
2\end{array}$ & Proteinuric hypertension, macerated stillbirth \\
\hline 13 & Unexplained $(\geqslant 2500 \mathrm{~g})$ & 38 & 2800 & $\begin{array}{l}30 \\
36\end{array}$ & $\begin{array}{l}0 \\
3\end{array}$ & Unexplained macerated stillbirth \\
\hline 14 & Unexplained $(\geqslant 2500 \mathrm{~g})$ & 39 & 4430 & $\begin{array}{l}32 \\
37 \\
40\end{array}$ & $\begin{array}{l}1 \\
1 \\
1\end{array}$ & Unexplained macerated stillbirth, no glucose tolerance studies performed \\
\hline 15 & Unexplained $(\geqslant 2500 \mathrm{~g})$ & 39 & 4250 & $\begin{array}{l}32 \\
37 \\
38\end{array}$ & $\begin{array}{l}1 \\
2 \\
3\end{array}$ & Unexplained macerated stillbirth \\
\hline 16 & Unexplained $(<2500 \mathrm{~g})$ & 38 & 1700 & 32 & $\begin{array}{l}1 \\
3\end{array}$ & $\begin{array}{l}\text { Recognised small for gestational age, reduced fetal movements, unexplained macerated } \\
\text { stillbirth }\end{array}$ \\
\hline 17 & Unexplained $(<2500 \mathrm{~g})$ & 33 & 1200 & 31 & 1 & $\begin{array}{l}\text { Thought to be congenital abnormality at birth, not confirmed at necropsy, stillbirth with } \\
\text { early maceration }\end{array}$ \\
\hline
\end{tabular}

ethnic origin was unexpected: only $8 \%$ of non-whites (predominantly from Asia) had grade 3 placental appearance at 34-36 weeks compared with $16 \%$ of whites. This was partly but not totally explained by the fact that the Asian women almost invariably did not smoke.

Before this study placental grading was already being used in clinical practice at Peterborough Maternity Hospital and no attempt was made to standardise the clinical response by the clinicians who knew the result. In fact the commonest response was additional oestriol estimations (table III).

Randomisation generated two trial groups that were comparable in important respects. The group where the clinician did not know the placental grading included slightly more young women who were in their first pregnancy, were of low social class, and were smokers. These minor imbalances, however, had no important effect on the conclusions drawn from the study. The trial was pragmatic and was superimposed on the ultrasound screening programme already in existence in the hospital. ${ }^{13}$ Of the women recruited to the study, $1910(96 \%)$ had been scanned early in pregnancy and $1753(88 \%)$ followed the hospital policy and had two or more scans after entry to the trial.

The choice of a combination of measures of outcome on which to base the main hypothesis reflected the need for an index frequent enough to allow a reasonable chance of identifying a clinically plausible effect. Furthermore, even using this index the trial was not statistically very powerful. This is reflected in the fact that the trial's estimated reduction in bad outcome of $14 \%$ was not significant. The observed difference in the stillbirth rate was significant but was not a formal prior hypothesis and this secondary analysis therefore generates rather than tests a hypothesis. The observed fivefold risk reduction for normally formed perinatal deaths is certainly an overestimate of the true effect of this test $(95 \%$ confidence interval of the relative risk 0.04 to 0.94 ). Nevertheless, the case review does suggest that some of the observed difference can be ascribed to the availability of the grading information.

This study alone does not justify routine scanning in late pregnancy. Further, larger randomised trials of placental grading are required. Nevertheless, these results do provide a basis for recommending that placental grading should be one of the indices reported during ultrasound examination in the third trimester.

We thank the following for their help: Josie Irving-Bell, Gillian Allan, Connie Bain, and Geraldine Ward of the Peterborough Scanning Department; David Felton, Brian Hackman, Jennifer Hughes-Nurse, and Barbara Skeet of Peterborough Maternity Hospital; Iain Chalmers, Diana Elbourne, Hazel Ashurst, Alan Lodwick, Lesley Mierh, Myrna Holmes, and our other colleagues at the National Perinatal Epidemiology Unit; Maws Ltd and the Royal College of Midwives for the award of the Maws research scholarship for 1983 to Jean Proud; the Department of Health and Social Security, which supports the National Perinatal Epidemiology Unit; and the East Anglian Regional Health Authority for very generous funding of the project.

\section{References}

1 Grannum PA, Berkowitz RL, Hobbins JC. The ultrasonic changes in the maturing placenta and their relation to fetal pulmonary maturity. Am $\mathcal{F}$ Obstet Gynecol 1979;133:915-22.

2 Quinlan RW, Cruz AL, Buhi WC, Martin M. Changes in placental ultrasonic appearance. I. Incidence of grade III changes in the placenta in correlation to fetal pulmonary maturity. $A m \mathcal{F}$ Incidence of grade III changes in
Obstet Gynecol 1982;144:468-70.

3 Quinlan RW, Cruz AL, Buhi WC, Martin M. Changes in placental ultrasonic appearance. II Pathologic significance of grade III placental changes. Am f Obstet Gynecol 1982;144:471-3.

4 Grannum PA, Hobbins JC. The placenta. Radiol Clin North Am 1982;20:353-65.

5 Kazzi GM, Gross TL, Sokol RJ, Kazzi NJ. Detection of intrauterine growth retardation: a new use for sonographic placental grading. Am $\mathcal{X}$ Obstet Gynecol 1983;145:733-7.

6 Miettinen O. Estimability and estimation in case-referent studies. Am $\mathcal{J}$ Epidemiol 1976;103. 226-35.

7 Secher NJ, Kern Hansen P, Lenstrup C, Pedersen-Bjergaard L, Sindberg-Erikson P. Birthweight for gestational age charts based on early ultrasound examination of gestational age. $\mathrm{Br}$ f Obstet Gynaecol 1986;93:128-34.

8 Baird D, Thomson AM. The survey perinatal deaths reclassified by special clinico-pathological assessment. In: Butler NR, Alberman ED, eds. Perinatal problems. Edinburgh: Livingstone, 1969:200-10.

9 Cole SK, Hey EN, Thomson AM. Classifying perinatal death: an obstetric approach. Br $\mathcal{J}$ Obstet Gynaecol 1986;93:1204-12.

10 Hill LM, Breckle R, Ragozzino MW, Wolfgram KR, O’Brien PC. Grade 3 placentation: incidence and neonatal outcome. Obstet Gynecol 1983;61:728-32.

11 Ashton SS, Russo MP, Simon NV, Shearer DM. Relationship between grade III placentas and biparietal diameter determinations. $\mathcal{F}$ Ultrasound Med 1983;2:127-9.

12 Crawford DC, Fenton DW, Price WI. Ultrasonic tissue characterization of the placenta: is it of clinical value? $F C U$ 1985; 13:533-7.

13 Schwartz D, Flamart R, Lellouch J. Clinical trials. London: Academic Press, 1980.

(Accepted 29 April 1987) 